\title{
Presentación del Dossier
}

Desde la finalización de la dictadura cívico-militar iniciada en 1976, se experimentó en la Argentina un notorio interés por el estudio y la reflexión alrededor de la violencia política revolucionaria desarrollada durante sus años preexistentes. La lucha armada como estrategia y el derrotero de aquellas organizaciones simultáneamente politicas y militares (OPM) se transformaron en temáticas abordadas cada vez con mayor frecuencia. Estos tópicos concitaron un atractivo no sólo historiográfico sino también por parte de otras disciplinas, como la sociología, la antropología y las ciencias políticas, a la vez que compartieron el escenario con una importante variedad de intervenciones entre las que destacan las memorias testimoniales y los abordajes periodísticos.

En los inicios de un nuevo orden institucional en los albores de los años 80, de la mano de autores como Carlos Brocato o Pablo Giussani, entre otros, se destacó una producción crítica (en algunos casos autocrítica dada su trayectoria politica) de aquellas experiencias, caracterizadas como foquistas y vanguardistas. El mesianismo de las OPM, su ponderación del coraje por sobre la política, la existencia de una derrota moral y, sobre todo, la problemática del militarismo fueron algunas de las conceptualizaciones imperantes en este tipo de análisis. Paulatinamente, y como contracara, aparecieron diversas historias testimoniales que, legitimando el derrotero de estas estructuras, se convirtieron en un insumo alternativo para el conocimiento de estas experiencias.

Con mayor diversidad de fuentes documentales, excediendo lo testimonial, comenzó a ganar terreno el abordaje historiográfico profesional. Aún con herramientas metodológicas luego perfeccionadas, los trabajos de Richard Gillespie sobre la organización Montoneros y de Pablo Pozzi sobre el PRT-ERP, junto a la paulatina aparición de otras investigaciones, dieron cuenta de un quiebre en la construcción del relato histórico.

Sin embargo, será la crisis política y social que estalló en el año 2001 uno de los factores que determine una clara línea divisoria en lo relativo a

(Archivos, año V, $\mathrm{n}^{\circ}$ 9, septiembre de 2016, pp. 9-12) 
las preocupaciones historiográficas antes vigentes. La revalorización por la radicalización de los años 60 y 70, con la emergencia de nuevos actores políticos y sociales que, bajo diversas premisas teórico-conceptuales, pugnaron por un cambio social, redundaron en el deseo de un mayor conocimiento sobre un período también convulsionado que posibilitaba, a su vez, una mejor comprensión del presente. Así, se multiplicaron los estudios sobre las OPM incluyendo trabajos académicos en el ámbito universitario, mesas temáticas particulares en diversas jornadas, publicación de revistas especializadas y dedicadas exclusivamente a tales tópicos, entre otros ejemplos.

En este marco, la historia de las OPM comenzaron a ser abordadas desde diversas perspectivas e intereses: los estudios de género que ponderaron la reflexión sobre el papel de las mujeres, los trabajos en clave regional (que tomaron experiencias geográficamente específicas de las diversas organizaciones) o los análisis discursivos que indagaron prioritariamente sobre las subjetividades y los aspectos identitarios de estas estructuras. Ahora bien, este vasto campo se vio acompañado, simultáneamente, por una abundante producción de tipo ensayistica y periodística que, muchas veces en clave laudatoria y con escaso bagaje documental, logró una difusión masiva. Ello se vio complementado, durante los años kirchneristas, por la construcción de un forzado imaginario que pretendió anclar su propia experiencia al pasado militante setentista.

Sin embargo, la proliferación y el crecimiento cuantitativo de producciones referidas a estos tópicos no supuso que el campo historiográfico sobre la lucha armada en los años 60 y 70 esté al margen de la necesidad de un profundo desarrollo de sus temáticas. En relación con ello, es notorio aún el desnivel existente entre la producción sobre Montoneros y el PRT-ERP con respecto a las restantes OPM. Si bien esto recae en una lógica cuantitativa por tratarse de las organizaciones con mayor militancia, y por lo tanto con un reservorio de fuentes documentales más amplio, no es menos cierto que otras estructuras, también de alcance nacional, tuvieron desarrollos de importancia.

De igual manera, la abundancia de estudios que primaron el análisis discursivo de las organizaciones, no elimina la necesidad de profundización de aquellos debates teórico-conceptuales que, alrededor de la lucha armada y la violencia política como estrategia revolucionaria, se produjeron dentro de las OPM, o bien entre ellas. Al mismo tiempo, y en consonancia con esta problemática, no es menor el enorme campo de discusión que desató en estas agrupaciones la significación del peronismo y su retorno al poder en los años 70 .

Seguramente, una de las tareas pendientes más relevantes sea profundizar la inserción que las OPM forjaron en una clase obrera a la que 
pretendian dirigir e influir. Ninguna de las organizaciones existentes actuó en un vacío y todas ellas, en mayor o menor medida, se nutrieron de diversos componentes de un proletariado radicalizado. Indagar sobre el accionar de las estructuras político-militares en los organismos sindicales de base, su participación en conflictos específicos o los mecanismos para forjar una influencia en los ámbitos fabriles, son algunas de las temáticas que aguardan ser abordadas. De igual modo, resulta llamativa la ausencia de producciones sistemáticas que den cuenta de la relación y estrategias de inserción de las OPM en el movimiento estudiantil en particular y en la juventud en general (más teniendo en cuenta que se trató de un sujeto de relevancia para el crecimiento de estas estructuras). Es en relación con estos vacíos que resulta una tarea esencial una sistemática profundización de los diversos frentes de masas que las organizaciones pretendieron desarrollar.

En el presente dossier, se optó por un conjunto de trabajos seleccionados con objetivos diversos. Por un lado, se presentan dos artículos de corte historiográfico que, respectivamente, se proponen analizar críticamente la amplia producción existente sobre la lucha armada y el papel de las OPM. Eduardo Rey Tristán y Verónica Oikión Solano presentan un minucioso balance en perspectiva latinoamericana sobre la amplia bibliografia existente alrededor de la problemática en torno a la lucha armada desde la Revolución Cubana hasta la actualidad. Por su parte, Gabriel Rot hace lo propio para referirse al amplio universo historiográfico presente en la Argentina y a las diversas líneas de análisis que imperaron en las últimas décadas dando cuenta, a su vez, de los alcances y perspectivas existentes en este campo. La lectura conjunta de ambos trabajos se convierte en un relevante insumo para dar cuenta de cuál es el estado de avance del campo historiográfico latinoamericano y argentino sobre estas temáticas, cuáles fueron las líneas de análisis centrales hasta el momento y qué aspectos resultan factibles y necesarios de profundizar.

En otro orden, los artículos de Federico Cormick y Carlos Ignacio Custer brindan al dossier la posibilidad de indagar sobre el derrotero de dos organizaciones político-militares escasamente estudiadas como lo fueron, respectivamente, la Organización Comunista Poder Obrero (OCPO) y las Fuerzas Armadas Revolucionarias (FAR). Estos artículos permiten visualizar las variantes y los matices (teórico-ideológicos y metodológicos) que existieron en el amplio universo de las organizaciones armadas presentes en el período más allá de las dos estructuras mayoritarias ampliamente estudiadas. Simultáneamente, ambos trabajos posibilitan también una mejor comprensión del clima de ideas dentro de una coyuntura en la que diversas corrientes y dirigentes experimentaron un proceso de deriva ideológica del marxismo hacia el peronismo con 
el objeto de una fusión teórica de ambos bagajes (como pretendieron las FAR), o bien, de intento de acercamiento a la militancia peronista en la búsqueda de su radicalización y giro a la izquierda (como es el caso del OCPO).

En otro orden, el artículo de Cormick conlleva el valor agregado de indagar sobre la participación de una OPM en un espacio de coordinación de diversas estructuras políticas, organismos sindicales de base y personalidades como lo fue el Frente Antiimperialista y por el Socialismo (FAS), lo que permite romper con los estudios de diversas estructuras político-militares que se limitan a análisis de las propias organizaciones desanclados de la coyuntura política y del movimiento social existente. En una línea similar, el artículo de Mariano Casco Peebles y María Agustina Leunda tiene la importancia de abordar una experiencia concreta de inserción de las OPM en el mundo fabril, particularmente, en el marco de un conflicto obrero como lo fue la huelga de la planta de Mercedes Benz en 1975. Se trata de un estudio de caso en el que los autores polemizan con aquellas teorias que sostienen que el papel de las organizaciones armadas se producia al margen, o incluso era nocivo, a las acciones de masas existentes.

En definitiva, este dossier pretende ser un aporte al campo de estudio sobre las OPM y la lucha armada en los años 60 y 70 desde miradas que no prioricen el debate sobre la violencia politica, ya sea desde una critica moral o impugnatoria, o bien, desde las reivindicaciones heroicas de las diversas experiencias, sino que avance en los estudios sistemáticos y fundados, anclados en el contexto social y en la coyuntura política, preguntándose, a su vez, de qué modo y en qué medida estas estructuras se vincularon a la lucha de clases y aportaron (o no) a su desarrollo.

Gabriel Rot y Martin Mangiantini 